\title{
Survey on Intestinal Helminthic Infection Status of Students in Two Counties, Hadong-gun and Goseong-gun, Korea
}

\author{
Young Yil Bahk', Yun-Kyu Park2 , Byoung-Kuk Na, ${ }^{3,4}$, Woon-Mok Sohn ${ }^{3}$, Sung-Jong Hong ${ }^{5}$, \\ Jong-Yil Chai6, Tong-Soo Kim ${ }^{2 * *}$ \\ ${ }^{1}$ Department of Biotechnology, College of Biomedical and Health Science, Konkuk University, Chungju 27478, Korea; '2Department of Parasitology \\ and Tropical Medicine, Inha University School of Medicine, Incheon 22212, Korea; ${ }^{3}$ Department of Parasitology and Tropical Medicine, and Institute \\ of Health Sciences, Gyeongsang National University School of Medicine, Jinju 52727, Korea; ' ${ }^{4}$ K21 Plus Team for Anti-aging Biotechnology and \\ Industry, Department of Convergence Medical Science, Gyeongsang National University, Jinju 52727, Korea; ${ }^{5}$ Department of Medical Environmental \\ Biology and Research Center for Biomolecules and Biosystems, Chung-Ang University College of Medicine, Seoul 06974, Korea; ${ }^{6}$ Korea \\ Association of Health Promotion, Seoul 07653, Korea
}

\begin{abstract}
This study was conducted to investigate the prevalence of intestinal parasites among students from Goseonggun, Gangwon-do and Hadong-gun, Gyeongsangnam-do as typical low and high endemic counties. From May to July 2017, a total of 2,033 fecal samples were collected at 27 elementary, 10 junior high, and 8 high schools from 2 counties and examined by the Kato-Katz technique for egg-positive surveys (Collection rate: 37.02\% [2,033/5,492]). Of the participants examined, $13(0.64 \%)$ were found to harbor eggs of 3 parasitic species, Trichuris trichiura, Clonorchis sinensis and Metagonimus yokogawai. Based on the regional distribution, the egg-positive rate in Goseong-gun was 0\% (0/550) and that in Hadong-gun was $0.88 \%(13 / 1,483)$. The positive rates for C. sinensis, M. yokogawai, and T. trichiura in Hadonggun were $0.20 \%(3 / 1,483), 0.61 \%(9 / 1,483)$, and $0.07 \%(1 / 1,483)$, respectively. The present survey showed that the prevalence of parasitic infection among students is currently very low even in remote, previously endemic areas, and the present status of parasitic diseases can be summarized as some transmission of fish/food-borne trematodes. Thus, it is necessary to carefully, continuously monitor the trematode infection status, particularly of $C$. sinensis and $M$. yokogawai.
\end{abstract}

Key words: Intestinal helminthic, student, egg-positive, survey, endemic, non-endemic

\section{INTRODUCTION}

Intestinal parasitic infections by helminths and protozoa are among the most prevalent infections worldwide [1]. Previously, Korea had a high intestinal helminth infection rate [2,3]. According to national-wide prevalence surveys, the egg-positive rate of helminthic infections was $90.5 \%$ in $1969,84.3 \%$ in $1971,63.2 \%$ in $1976,41.1 \%$ in 1981 , and $12.9 \%$ in $1986[4,5]$. However, Korea is one of the Asian countries that has successfully controlled intestinal parasitic infections through remarkable economic development, as demonstrated by nationalwide surveys every 5 years since 1971 . According to the 8th National-Wide Survey in Korea, a nation approved statistics program, despite the remarkable decrease of intestinal parasitic in-

- Received 21 March 2018, revised 19 July 2018, accepted 15 August 2018.

*Corresponding author (tongsookim@inha.ac.kr)

(c) 2018, Korean Society for Parasitology and Tropical Medicine

This is an Open Access article distributed under the terms of the Creative Commons Attribution Non-Commercial License (http://creativecommons.org/licenses/by-nc/4.0) which permits unrestricted non-commercial use, distribution, and reproduction in any medium, provided the original work is properly cited. fections and soil-transmitted nematodes, the egg-positive rate was still $2.6 \%$ in 2012, fish/food-mediated parasite infections continue to persist or be detected, and infection with Trichuris trichiura, a soil-transmitted parasite, is gradually increasing [5]. Despite continued intestinal parasitic control projects and national surveys of human intestinal parasite prevalence, the estimated number of positive populations of some parasites, particularly Clonorchis sinensis and Gymnophalloides seoi, remains at 1 million cases. Therefore, studies of inhabitants in areas where intestinal parasites are known to be present as highly endemic foci or suspected endemic areas and their control regions should be investigated. In addition, the inhabitants of highly endemic areas should be systematically managed.

Thus, in this study, a complete survey of student groups in highly endemic and non-endemic areas was conducted to identify the present status of intestinal parasites infections and current pandemic status of the 2 groups through parasitebased analysis. National surveys do not provide accurate prevalence figures in endemic areas. 


\section{MATERIALS AND METHODS}

\section{Study region}

This study was conducted in Goseong-gun and Hadonggun. These areas have a total land area of 664.2 and $675.5 \mathrm{~km}^{2}$ and populations of 29,110 and 48,533 as of July 2017, respectively. Goseong-gun, known as a parasite cleansing site traditionally, is in the northernmost frontier of Gangwon-do Administrative District $\left(128^{\circ} 13^{\prime}-128^{\circ} 35^{\prime} \mathrm{E}\right.$ and $\left.38^{\circ} 11^{\prime}-38^{\circ} 36^{\prime} \mathrm{N}\right)$ and the East Sea. Forty-six percent of this land is restricted as a military protection area. Hadong-gun is in the southern tip of the Korean peninsula, in the southern part of Gyeongsangnam-do Administrative District (127 $56^{\prime} \mathrm{E}$ and $34^{\circ} 55^{\prime}-35^{\circ} 19^{\prime}$ $\mathrm{N})$. Hadong-gun is traditionally known as a region where intestinal parasites are prevalent. Especially in the case of Clonorchis sinensis, infection rate was $15-25 \%$. This focus is adjacent to the Gwangyang-gun and Gurye-gun, Jeollanam-do Administrative Districts on the border of the Seomjin river, with Jinju and Sacheon-si to the east and Namhae-gun to the south.

\section{Subjects}

This study was conducted with extensive cooperation from local schools comprised of elementary, junior high, and high school students. Participants in Goseong-gun were from $13 \mathrm{el}-$ ementary schools, 4 junior high schools, and 4 high schools, while those in Hadong-gun were from 14, 6, and 4 schools, respectively. Table 1 presents data for the subjects in this study and collection rates by school year and schools.

\section{Stool sample collection, mass stool examination and treatment}

A total of 2,033 fecal samples were collected from the study population: 550 from Goseong-gun (Collection rate: 550/2,433 [22.6\%]) and 1,483 from Hadong-gun (1,483/3,059 [48.48\%]). The samples were examined using the medical general laboratory method described in the WHO Bench Aids for the Diag- nosis of Intestinal Parasites. The sediment was examined under a light microscope using the Kato-Katz technique [6]. One Kato-Katz slide was prepared for each sample. Microscopic reading of the slides was conducted on the same day of processing approximately $2 \mathrm{hr}$ after preparation, particularly to detect hookworm eggs which may be affected by the clearing effect of glycerin. Helminth eggs were identified by their size and distinctive morphological features. Raw egg counts were multiplied by 21 , a constant value, to derive the number of eggs per gram (EPG) in the stool. Experienced microscopists from the Department of Parasitology and Tropical Medicine, Inha University processed and examined the stool specimens. Intestinal parasite species examined in this study were Ascaris lumbricoides, Ancylostoma duodenale, Trichuris trichiura, Trichostrongylus orientalis, Enterobius vermicularis, C. sinensis, Paragonimus westermani, Metagonimus yokogawai, Gymnophalloides seoi, Diphyllobothrium latum, and Taenia spp.

\section{Ethical considerations}

The study procedures involving human stool sample collection, laboratory investigation, interviews, and questionnaires were reviewed and approved by the Institutional Review Board of Inha University and conducted according to the principles expressed in the 1964 Helsinki Declaration. All participants who agreed to participate in this study were asked to read through the participant information sheet explaining the objectives, procedures, possible risks, and benefits of the research project. Signed consent forms were obtained from participants themselves and their parents or student's guardians prior to fecal sample submission and personal information talking was obtained through interviews and questionnaires.

\section{RESULTS}

\section{Demographic information of participants}

Through interviews and information in schools in Goseong-

Table 1. Subject of investigation and collection rate of fecal samples from each county by school grade

\begin{tabular}{|c|c|c|c|c|c|c|c|c|c|c|c|c|c|c|c|c|c|}
\hline \multirow{2}{*}{\multicolumn{2}{|c|}{ Area Grade }} & \multicolumn{7}{|c|}{ Elementary School } & \multicolumn{4}{|c|}{ Junior High School } & \multicolumn{4}{|c|}{ High School } & \multirow{2}{*}{ Total } \\
\hline & & $1 \mathrm{st}$ & 2nd & $3 r d$ & 4 th & 5th & 6th & Total & $1 s t$ & 2nd & $3 r d$ & Total & $1 s t$ & 2nd & 3rd & Total & \\
\hline \multirow{2}{*}{ Goseong } & Subject & 181 & 181 & 177 & 172 & 182 & 154 & 1,047 & 152 & 183 & 195 & 530 & 287 & 295 & 274 & 856 & 2,433 \\
\hline & $\begin{array}{l}\text { Collection } \\
\text { (Rate) }\end{array}$ & $\begin{array}{c}79 \\
(43.6)\end{array}$ & $\begin{array}{c}95 \\
(52.5)\end{array}$ & $\begin{array}{c}67 \\
(37.9)\end{array}$ & $\begin{array}{c}81 \\
(47.1)\end{array}$ & $\begin{array}{c}45 \\
(24.7)\end{array}$ & $\begin{array}{c}52 \\
(33.8)\end{array}$ & $\begin{array}{c}419 \\
(40.0)\end{array}$ & $\begin{array}{c}50 \\
(32.9)\end{array}$ & $\begin{array}{c}25 \\
(13.7)\end{array}$ & $\begin{array}{c}11 \\
(5.6)\end{array}$ & $\begin{array}{c}86 \\
(16.2)\end{array}$ & $\begin{array}{c}9 \\
(3.1)\end{array}$ & $\begin{array}{c}23 \\
(7.8)\end{array}$ & $\begin{array}{c}13 \\
(4.7)\end{array}$ & $\begin{array}{c}45 \\
(5.3)\end{array}$ & $\begin{array}{c}550 \\
(22.6)\end{array}$ \\
\hline \multirow[t]{2}{*}{ Hadong } & Subject & 282 & 258 & 272 & 287 & 299 & 285 & 1,683 & 208 & 234 & 230 & 672 & 274 & 219 & 211 & 704 & 3,059 \\
\hline & $\begin{array}{l}\text { Collection } \\
\text { (Rate) }\end{array}$ & $\begin{array}{c}168 \\
(59.6)\end{array}$ & $\begin{array}{c}136 \\
(52.7)\end{array}$ & $\begin{array}{c}157 \\
(57.7)\end{array}$ & $\begin{array}{c}125 \\
(43.6)\end{array}$ & $\begin{array}{c}145 \\
(48.5)\end{array}$ & $\begin{array}{c}121 \\
(42.5)\end{array}$ & $\begin{array}{c}852 \\
(50.6)\end{array}$ & $\begin{array}{c}92 \\
(44.2)\end{array}$ & $\begin{array}{c}99 \\
(42.3)\end{array}$ & $\begin{array}{c}110 \\
(47.8)\end{array}$ & $\begin{array}{c}301 \\
(44.8)\end{array}$ & $\begin{array}{c}128 \\
(46.7)\end{array}$ & $\begin{array}{c}123 \\
(56.2)\end{array}$ & $\begin{array}{c}79 \\
(37.4)\end{array}$ & $\begin{array}{c}330 \\
(46.9)\end{array}$ & $\begin{array}{l}1,483 \\
(48.5)\end{array}$ \\
\hline
\end{tabular}


Table 2. Number of helminth egg-positive cases by school grades in this survey

\begin{tabular}{|c|c|c|c|c|c|c|c|c|c|c|c|c|c|}
\hline \multirow{2}{*}{ Positive No. } & \multicolumn{6}{|c|}{ Elementary School } & \multicolumn{3}{|c|}{ Junior High School } & \multicolumn{3}{|c|}{ High School } & \multirow{2}{*}{ Tota } \\
\hline & $1 \mathrm{st}$ & 2nd & $3 r d$ & 4th & 5th & 6th & $1 s t$ & 2nd & 3rd & $1 \mathrm{st}$ & 2nd & 3rd & \\
\hline Goseong & 0 & 0 & 0 & 0 & 0 & 0 & 0 & 0 & 0 & 0 & 0 & 0 & 0 \\
\hline Hadong & 0 & 0 & 0 & 0 & 0 & 2 & 1 & 4 & 0 & 0 & 2 & 4 & 13 \\
\hline Subtotal & 0 & 0 & 0 & 0 & 0 & 2 & 1 & 4 & 0 & 0 & 2 & 4 & 13 \\
\hline
\end{tabular}

Table 3. Number of helminthic egg-positive stools

\begin{tabular}{|c|c|c|c|c|c|c|c|c|c|c|c|c|c|c|}
\hline & \multirow{3}{*}{$\begin{array}{c}\text { No. of } \\
\text { samples }\end{array}$} & \multirow{3}{*}{$\begin{array}{l}\text { No. of } \\
\text { egg-positive } \\
\text { cases }\end{array}$} & \multirow{3}{*}{$\begin{array}{l}\text { Positive } \\
\text { rate }\end{array}$} & \multicolumn{11}{|c|}{ Parasite } \\
\hline & & & & \multicolumn{5}{|c|}{ Nematoda } & \multicolumn{4}{|c|}{ Trematoda } & \multicolumn{2}{|c|}{ Cestoda } \\
\hline & & & & $A /^{*}$ & $H$ & $T t$ & To & Ev & Cs & $P w$ & My & Gs & $T$ spp. & $D /$ \\
\hline Goseong & 550 & 0 & 0 & 0 & 0 & 0 & 0 & 0 & 0 & 0 & 0 & 0 & 0 & 0 \\
\hline Hadong & 1,483 & 13 & 0.88 & 0 & 0 & $1(0.07)$ & 0 & 0 & $3(0.20)$ & 0 & $9(0.61)$ & 0 & 0 & 0 \\
\hline
\end{tabular}

${ }^{*}$ Al, Ascaris lumbricoides; H, Hookworm; Tt, Trichuris trichiura; To, Trichostrongylus orientalis; Ev, Enterobius vermicularis; Cs, Clonorchis sinensis; Pw, Paragonimus westermani; My, Metagonimus yokogawai; Gs, Gymnophalloides seoi; T spp., Taenia spp.; DI, Diphyllobothrium latum.

gun and Hadong-gun, data was obtained for 2,033 participants who underwent parasitological screening. A complete survey of the entire group of students in the highly endemic area of parasitic infection and those in the non-parasitic endemic area was carried out as a control group. These participants represented the young population in the 2 counties. Sampling of the participants was set up for all elementary (Goseong: 13 schools, and Hadong: 14), junior high (Goseong: 4 and Hadong: 6), and high (Go seong: 4 and Hadong: 4) schools within the survey areas. The distributions of the number of students were relatively uniform (Table 1).

\section{Positive rate and characteristics of intestinal parasites}

Of the 2,033 examined fecal samples from the surveyed participants, 13 were found to contain intestinal parasite eggs and the overall prevalence of parasitic infestations was $0.64 \%$. Eggs of 3 parasitic species were identified, including 1 nematode species (Trichuris trichiura) and 2 trematode species (C. sinensis and M. yokogawai). The most prevalent intestinal parasite found in the examined stools was M. yokogawai (9/13 cases, $69.23 \%$ ). The detailed results are shown in Tables 2, 3. Based on the regional distribution of the parasitic infections, the positive rate of parasitic infections in Goseong-gun was $0 \%$ (0/550 participants surveyed) and that in Hadong-gun was $0.88 \%(13 / 1,483)$. The egg-positive rates of fecal samples from Hadong-gun were $0.23 \%$ (2/852 participants) in elementary schools, $1.66 \%$ (5/301) in junior high schools, and 1.82\% (6/330) in high schools, respectively. The positive rates for $C$. sinensis and M. yokogawai were $0.20 \%$ and $0.61 \%$, respectively.
Table 4. Number and average of excreted eggs in the egg-positive stools

\begin{tabular}{lrrc}
\hline & $\begin{array}{c}\text { No. of positive } \\
\text { cases }\end{array}$ & $\begin{array}{c}\text { No. of total } \\
\text { excreted eggs }\end{array}$ & $\begin{array}{c}\text { Average of } \\
\text { the excreted } \\
\text { eggs }\end{array}$ \\
\hline Clonorchis sinensis & 3 & 82 & 27 \\
Metagonimus yokogawai & 9 & 847 & 94 \\
Trichuris trichiura & 1 & 2 & 2 \\
Total & 13 & 931 & \\
\hline
\end{tabular}

The mean intensities of infection were $27 \mathrm{EPG}$ for $C$. sinensis, 94 for M. yokogawai, and 2 for T. trichiura (Table 4). Performing fecal egg counts and conducting follow-up tests would have provided a more accurate picture of parasite management issues. For the classification of egg counts, 5 EPG gradings are used (I-IV) as important epidemiological indicators: (I: 21999, II: 1,000-4,999, III: 5,000-9,999, IV: 10,000-29,999, and V: $>30,000)$. A fecal egg count below grade III is considered light, grade IV is considered moderate range, and values above 30,000 are considered heavy. The mean EPG of 13 positive participants was 71.6, which represents early grade I (Table 4).

\section{DISCUSSION}

Korea was previously shown to be heavily endemic for various species of parasitic infestations for a long time. In this study, we selected 2 counties as low and high endemic counties. According to the 8th National-Wide Survey in Korea, the estimated positive rate in the Gangwon-do Administrative District was $0.0867 \%$, showing the lowest egg-positive rate [5]. 
The estimated positive rate in the Gyeongsangnam-do Administrative District was $6.98 \%$, which was the 3rd highest level, and the estimated number of infected individuals was approximately 227,000 . Seomjin river is a major river, and the eggpositive rate of population living in the river basins is high [7].

The present study involved surveys of intestinal parasites in 2 counties (Goseong-gun and Hadong-gun) as low and high endemic counties in Korea and revealed a considerably low prevalence of intestinal parasites (average of $0.64 \%$ in total participants, $0 \%$ in Goseong-gun, and $0.88 \%$ in Hadong-gun) among students, representing the young generation from the 2 counties. Human helminthiasis in Korea has been heavily endemic for a long time and is distributed along most river basins throughout the country. The rapid decrease in the overall prevalence of intestinal parasites over the past several decades has been achieved through the continuous efforts of a nationwide control program by the Korean government that mostly addressed students. In this study, the egg-positive case in Goseong-gun was not accurately determined. However, an apparent trend was revealed by the results. The prevalence of M. yokogawai was slightly higher than that of $C$. sinensis. This finding differs from the general trends. According to the 7th and 8th National-Wide Surveys in Korea, the total egg-positive rates of fish/food-borne trematodes, particularly C. sinensis, M. yokogawai, and G. seoi, were 2,89\% in the 7th National Survey and $2.14 \%$ in the 8th National-Wide Survey. In the 8th NationalWide Survey at 2012, the positive rates of C. sinensis, M. yokogawai, and G. seoi were found to be $1.86 \%, 0.26 \%$, and $0.02 \%$, respectively. In addition, the egg-positive rate of nematode, $T$. trichiura, was also extremely low $(0.07 \%$ over $0.41 \%$ in the 8 th National-Wide Survey [1/1,483 cases in Hadong-gun]). This result suggests that this nematode has been nearly eliminated. In fact, T. trichiura as well as C. sinensis and M. yokogawai are representative intestinal parasites in Korea [5]. This parasite had been not required management since the infection rate was continuously decreased according to the 6th NationalWide Survey (65.4\% in the 1st National-Wide Survey [1971], $42.0 \%$ [1976], 23.4\% [1981], 4.8\% [1986], 0.2\% [1992], and $0.04 \%$ in surveys in subsequent years [1997]), but increased again according to the 7th National-Wide Survey $(0.27 \%)$ and 8th National-Wide Survey ( $0.41 \%)$. The risk factors of T. trichiura infection in Korea remain unclear. Although this infection is not currently a serious concern, it is necessary to carefully and continuously monitor the infection status.

For age-dependent egg-positive rates, although the trend in egg-positive patterns according to age showed some similarities between this study and the national surveys, there was a considerable decrease in the egg-positive rate of fish/foodborne trematodes compared to that reported by the 8th National-Wide Survey. In the 8th National-Wide Survey, the agespecific positive rate was generally low in individuals less than 10 years old, but this rate increased during the teenage years. For $C$. sinensis, the egg-positive rate in those less than 10 years old was $0.11 \%$, while that in teenagers was $0.47 \%$ [ 5 ]. In contrast, individuals in their 20s, 30s, 40s, and 50s showed rates of $2.04 \%, 2.16 \%, 3.48 \%$, and $4.26 \%$. Our survey showed that the egg-positive rates of student groups for $C$. sinensis and $M$. yokogawai in Hadong-gun were $0.20 \%$ and $0.61 \%$, respectively, which are remarkably lower rate than those reported in the 7th and 8th National-Wide Surveys. Generally, the infection rate of $C$. sinensis has the largest influence on the overall nationwide parasite-positive rate, as this liver fluke infection typically accounts for the largest proportion of infections in Korea [7]. It is well-known that fish/food-borne parasitic infections including $C$. sinensis are high in riverside regions. The risk factors for C. sinensis infestation in Korea have been widely examined in epidemiological studies. Particularly, in Hadong-gun, where residents consume large amounts of fish and utilize unique cuisine methods, the infection-positive rate for $\mathrm{C}$. sinensis is higher than that in other regions of Korea because of differences in eating patterns and elimination of previously prevalent helminthiases throughout the country [8]. Metagonimus yokogawai is a fish-borne trematode that is medically important in Korea. Since Yeo and Seo reported a high endemic area of M. yokogawai near Seomjin river, numerous surveys have revealed endemic areas along the southern and eastern coasts of Korea where the sweet fish (Plecoglossus altivelis) is available $[2,9]$. This species is hermaphroditic and capable of self-fertilization. Embryonated eggs are passed into the aquatic environment (fresh or brackish water), each containing a fully developed larva known as a miracidium.

The prevalence of the parasites determined in this study do not reflect the actual status of infection because the examination was performed only using the Kato-Katz technique.

In conclusion, the present survey shows that the prevalence of parasitic infection is currently very low even in remote, previously endemic areas and the present status of parasitic diseases in students from the surveyed counties revealed some transmission of fish/food-borne trematodes, as previously described [8]. Currently, C. sinensis and M. yokogawai are 2 major helminthes 
with a pattern of parasitic diseases that has changed in a manner commensurate with environmental and society-based changes as well as with economic development. These helminths are transmitted by freshwater fishes, and local populations prefer to consume raw fish as recreation or epicureanism. Infections are contracted by eating undercooked fishes that use metacercariae. Contaminated fishes are mainly found in streams and rivers where freshwater snails thrive. Thus, it is necessary to carefully and continuously monitor the trematode infection status, particularly of C. sinensis and M. yokogawai.

\section{ACKNOWLEDGMENTS}

We are grateful to all blood donors and the staff of the Public Health Centers in Goseong-gun and Hadong-gun. This study was supported by a grant from the Korea Association of Health Promotion (2017-02) and by the National Research Foundation of Korea (NRF) grants funded by the Korea Government (NRF-2017M3A9B8069530) in sample collection.

\section{CONFLICT OF INTEREST}

We have no competing interest related to this work.

\section{REFERENCES}

1. Savioli L, Albonico M, Engels D, Montresor A. Progress in the prevention and control of schistosomiasis and soil-transmitted helminthiasis. Parasitol Int 2004; 53: 103-113.

2. Seo BS, Lee SH, Cho SY, Chai JY, Hong ST, Han IS, Sohn JS, Cho BH, Ahn SR, Lee SK, Chung SC, Kang KS, Shim HS, Hwang IS. An epidemiologic study on clonorchiasis and metagonimiasis in riverside areas in Korea. Korean J Parasitol 1981; 19: 137-150.

3. Seo BS. Epidemiology and control of ascariasis in Korea. Korean J Parasitol 1990; 28: 49-61.

4. Ministry of Health and Social Affairs and Korean Association of parasite Eradication. Prevalence of intestinal parasitic infections in Korea - The 2nd report. Seoul, Korea. 1976, pp 1-147 (In Korean).

5. Korea Centers for Disease Control and Prevention. Korea Association of Health Promotion: Prevalence of intestinal parasites in Korea - The 8th Report. Seoul, Korea. 2012.

6. World Health Organization. Bench Aids for the Diagnosis of Intestinal Parasites. Geneva, Switzerland. World Health Organization. 1994.

7. Cho SH, Lee KY, Lee BC, Cho PY, Cheun HI, Hong ST, Sohn WM, Kim TS. Prevalence of clonorchiasis in Southern endemic areas of Korea in 2006. Korean J Parasitol 2008; 46: 133-137.

8. Hong ST, Chai JY, Choi MH, Huh S, Rim HJ, Lee SH. A successful experience of soil-transmitted helminth control in the Republic of Korea. Korean J Parasitol 2006; 44: 177-185.

9. Yeo TO, Seo BS. Study on Metagonimus yokogawai (Katsurada, 1912) in Korea. III. Epidemiological observation of human Metagonimus infection in Hadong area, South Kyongsang Do. Seoul J Med 1971; 12: 259-267. 
